\title{
Estrutura e Sentimento: relações retóricas em comentários opinativos no Facebook
}

\author{
Juliano Desiderato ANTONIO*
}

* Doutor (2004) em Linguística e Língua Portuguesa pela Universidade Estadual Paulista Júlio de Mesquita Filho (Unesp). Professor Associado da Universidade Estadual de Maringá (UEM). Contato: jdantonio@uem.br.

\begin{abstract}
Resumo:
$\mathrm{O}$ uso das redes sociais vem crescendo vertiginosamente nos últimos anos. O Facebook, por exemplo, registrou mundialmente uma média de 1,47 bilhões de usuários ativos ao dia e de 2,23 bilhões ao mês em junho de 2018. Diante da enorme quantidade de usuários conectados às redes sociais, surgiu, por parte dos departamentos de marketing de grandes corporações e de analistas políticos, o interesse por minerar as opiniões dos usuários das redes a respeito de produtos, serviços, temas debatidos na sociedade, imagem de personalidades etc. $\mathrm{Na}$ análise de sentimentos, a descrição dos meios gramaticais e lexicais de expressão da subjetividade é utilizada para a criação de aplicações que realizem a análise automaticamente, permitindo, por exemplo, a prever tendências financeiras, intenções de voto, identificar a avaliação de produtos disponíveis online, como livros, filmes etc. Tomando como base a Rhetorical Structure Theory (RST), teoria descritiva que investiga a organização dos textos caracterizando as relações que se estabelecem entre as partes do texto, este trabalho tem como objetivo descrever as relações que emergem de comentários avaliativos em páginas públicas de empresas no Facebook.
\end{abstract}

\section{Palavras-chave:}

Análise de sentimentos. Rhetorical Structure Theory. Facebook.

Signum: Estudos da Linguagem, Londrina, v. 23, n. 2, p. 100-113, ago. 2020

Recebido em: 04/05/2020

Aceito em: 02/07/2020 


\title{
Estrutura e Sentimento: relações retóricas em comentários opinativos no Facebook
}

\author{
Juliano Desiderato Antonio
}

\section{CONSIDERAÇões INICIAIS}

O uso das redes sociais vem crescendo vertiginosamente nos últimos anos. O Facebook, por exemplo, registrou mundialmente uma média de 1,47 bilhões de usuários ativos ao dia e de 2,23 bilhões ao mês em junho de 2018. Nesse mesmo período, no Brasil, a média diária foi de 93 milhões de pessoas, e a mensal, de 127 milhões (FACEBOOK, 2018). Na abrangente revisão de Wilson, Gosling e Graham (2012) sobre as pesquisas científicas realizadas acerca do Facebook, os autores mencionam a necessidade de engajamento social como uma das maiores motivações para o uso dessa rede social. De acordo com Seidman (2014), pesquisas empíricas realizadas revelaram que muitas pessoas conseguem expressar seu "verdadeiro eu" online com maior facilidade do que em interações face a face.

Diante da enorme quantidade de usuários conectados às redes sociais, surgiu, por parte dos departamentos de marketing de grandes corporações e de analistas políticos, o interesse por minerar as opiniões dos usuários das redes a respeito de produtos, serviços, temas debatidos na sociedade, imagem de personalidades etc (de acordo com Hogenboom et al., 2015), 1/3 das postagens em blogs e 1/5 dos tweets discutem produtos ou marcas). Esse novo campo de estudos, denominado Análise de Sentimentos (TABOADA, 2016), encontrase posicionado na interseção entre a Linguística e a Ciência da Computação. Nesse domínio, o termo "sentimento" é compreendido de forma restrita como avaliação positiva, negativa ou neutra, e cabe ao linguista descrever os recursos do léxico e da gramática para expressão da avaliação subjetiva.

Ainda de acordo com Taboada, várias categorias investigadas pela Linguística integram o escopo de estudos da análise de sentimentos como, por exemplo, a subjetividade (TRAUGOTT, 2010), a evidencialidade (DE HAAN, 2001) e a modalidade (PALMER, 1986). A principal diferença entre as abordagens reside no fato de que, na análise de sentimentos, a descrição dos meios gramaticais e lexicais de expressão da subjetividade é utilizada para a criação de aplicações que realizem a análise automaticamente, permitindo, por exemplo, a prever tendências financeiras, intenções de voto, identificar a avaliação de produtos disponíveis online, como livros, filmes etc.

Ao tratar dos métodos computacionais para análise de sentimentos, Taboada (2016) destaca as abordagens baseadas no léxico. Para analisar um enunciado, a aplicação busca em um dicionário a polaridade das palavras (por exemplo, a palavra excelente tem polaridade positiva, e a palavra horrivel tem polaridade negativa). Por meio de algoritmos que calculam os valores positivos e os valores negativos das palavras em um texto, a aplicação fornece a orientação geral do texto.

De acordo com Taboada (2016), inicialmente concentrou-se muito esforço no estudo da orientação semântica dos adjetivos, uma vez que essa classe de palavras é responsável por grande parte da carga subjetiva de um texto. Com o passar do tempo, outras classes de palavras foram incorporadas aos dicionários de análise de sentimentos: substantivos (obra-prima, desastre), verbos (amar, odiar), advérbios (babilmente, pobremente) etc.

No entanto, como alertam Alkorta et al. (2015), a orientação semântica positiva ou negativa pode ser obtida não apenas a partir da análise de itens lexicais. Para este trabalho, interessa a análise no nível da estrutura discursiva, a saber, as relações implícitas que emergem da combinação entre as partes do texto, e 
que, de acordo com Trnavac e Taboada (2014), podem (i) reverter a polaridade, (ii) intensificar a polaridade ou (iii) modular a polaridade.

Tomando como base a Rhetorical Structure Theory (RST), teoria descritiva que investiga a organização dos textos caracterizando as relações que se estabelecem entre as partes do texto (MANN; THOMPSON, 1988), este trabalho tem como objetivo descrever as relações que emergem de comentários avaliativos em páginas públicas de empresas no Facebook.

Em termos de estrutura, este trabalho está dividido em mais três seções além desta introdução. $\mathrm{Na}$ Fundamentação Teórica, apresentam-se os pressupostos básicos da RST, teoria que embasa o trabalho. Em seguida, os procedimentos metodológicos para realização da pesquisa são explicitados, desde a coleta do corpus até as ferramentas utilizadas para tabulação das ocorrências. Os resultados obtidos são discutidos na seção posterior à Metodologia e, finalmente, encerra-se o trabalho com as Considerações Finais.

\section{FundamentaÇão Teórica}

De acordo com Matthiessen (2005), a RST surgiu das pesquisas relacionadas ao estudo da organização textual tendo em vista a geração automática de textos. A RST tem como principal conjetura o fato de que as orações de um texto veiculam mais do que apenas conteúdo proposicional explícito. Da combinação entre as orações e as partes de um texto surgem proposições implícitas, as chamadas proposições relacionais, que recebem outros rótulos como "relações retóricas", "relações discursivas", "relações de coerência" (TABOADA, 2009, p. 127).

Uma lista de 32 relações pode ser encontrada no website da teoria ${ }^{1}$. No entanto, como apontam Mann e Thompson (1988), essa lista não representa um rol fechado, e mais relações podem ser acrescentadas.

Em termos de organização, as relações podem ser de dois tipos:

a) núcleo-satélite, nas quais uma porção do texto (satélite) é ancilar da outra (núcleo), como na Figura 1, a seguir, em que um arco vai da porção que serve de subsídio para a porção que funciona como núcleo.

b) multinucleares, nas quais uma porção do texto não é ancilar da outra, sendo cada porção um núcleo distinto, como na Figura 2:

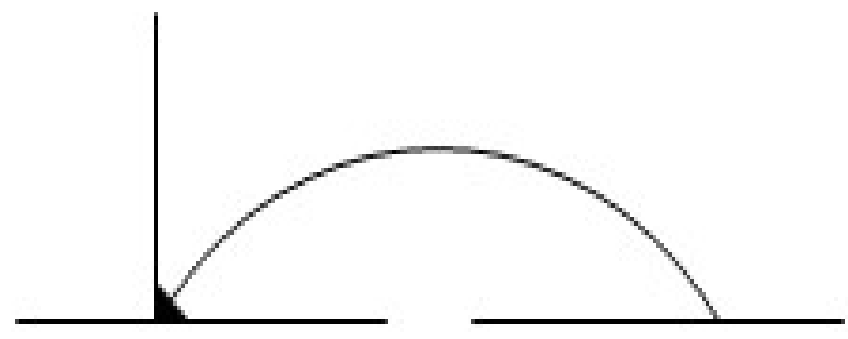

Fonte: Mann e Thompson, 1988.

Figura 1 - Relação núcleo-satélite

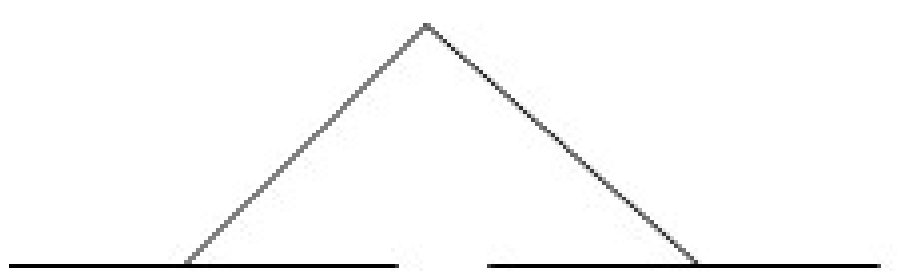

Figura 2 - Relação multinuclear

A estrutura retórica de um texto é representada por um diagrama arbóreo e é definida pelas redes de relações que se estabelecem entre porções de texto sucessivamente maiores. Segundo Mann e Thompson (1988), a estrutura retórica é funcional, pois leva em conta como o texto produz um efeito sobre o enunciatário, ou seja, toma como base as funções que as porções do texto assumem para que o texto atinja o objetivo global

\footnotetext{
${ }^{1}$ Disponível em: www.sfu.ca/rst.
} 
para o qual foi produzido. Na Figura 3, pode-se observar a estrutura retórica de um comentário avaliativo do corpus deste trabalho.

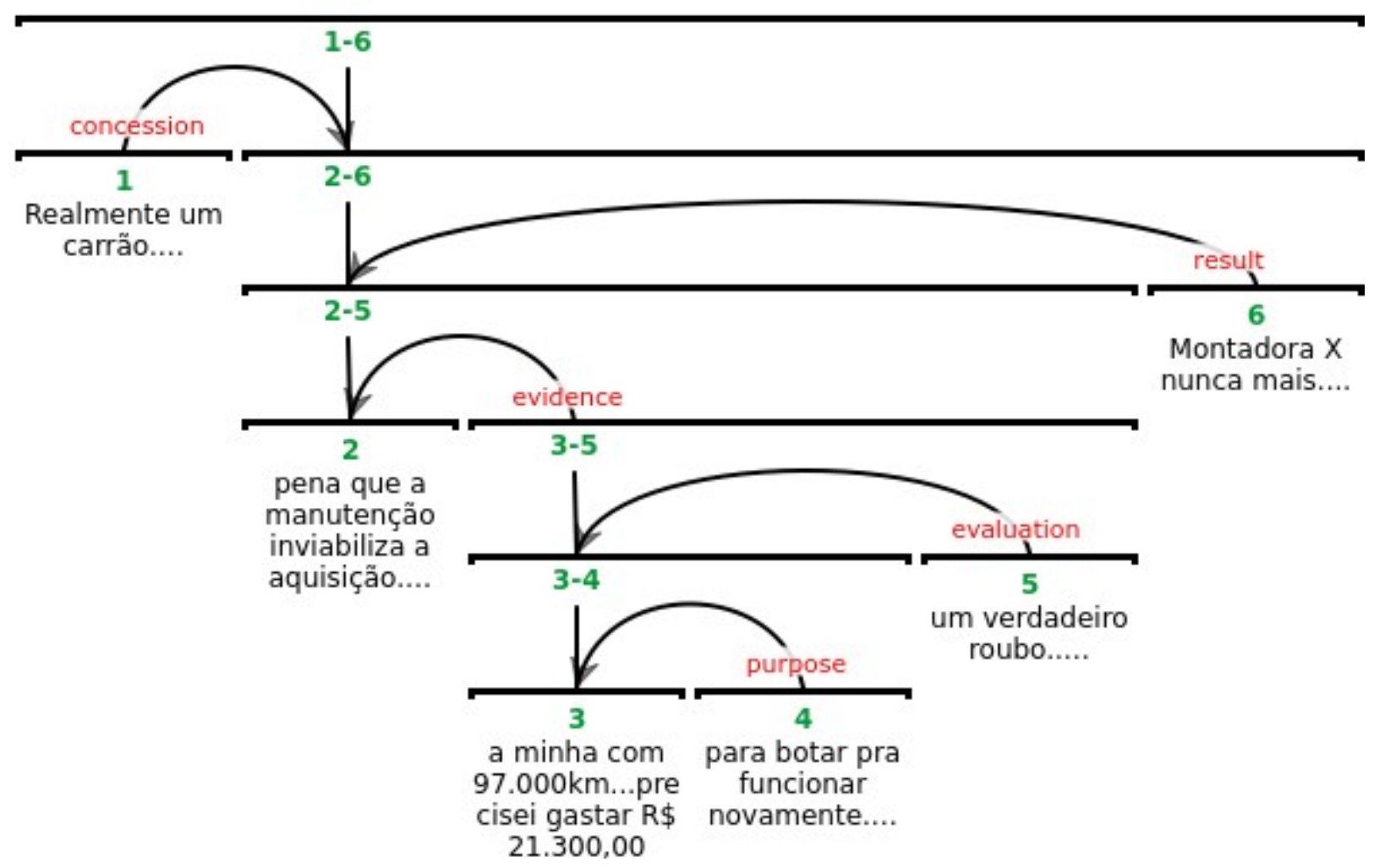

Fonte: Elaborada pelo autor.

Figura 3 - Diagrama da estrutura retórica de uma ocorrência do corpus $^{2}$

No exemplo apresentado, pode-se observar que todos os satélites apontam para a unidade 2, a porção considerada mais central para os propósitos autor da avaliação. A relação que se estabelece entre a unidade 1 e as demais unidades do texto é a de concessão ${ }^{3}$, ou seja, o autor reconhece que o automóvel sobre o qual ele fala é bom, "um carrão", mas tem como intenção levar seu destinatário a aceitar o conteúdo do núcleo ("a manutenção inviabiliza a aquisição"), contraditório em relação à afirmação inicial. Para aumentar a crença do destinatário no conteúdo do núcleo, o autor da avaliação apresenta uma evidência, a de que gastou 21.300 reais para colocar o carro para funcionar novamente. Na avaliação do autor, trata-se de "um verdadeiro roubo", cujo resultado é nunca mais adquirir um carro da montadora $\mathrm{X}^{4}$.

\section{Metodologia}

O percurso metodológico da pesquisa cujos resultados são apresentados neste trabalho compreende cinco etapas: coleta das ocorrências, segmentação, identificação da unidade central (UC), determinação da polaridade e tabulação.

\footnotetext{
${ }^{2}$ O diagrama foi criado utilizando-se a ferramenta rst-Web (ZELDES, 2016).

${ }^{3}$ Os nomes das relações estão em inglês devido ao software utilizado para elaborar os diagramas.

${ }^{4}$ Os nomes das empresas e produtos avaliados foram omitidos das ocorrências.
} 
As 492 ocorrências de comentários avaliativos foram coletadas em páginas públicas do Facebook pertencentes a empresas de várias áreas de atuação como montadoras de automóveis, operadoras de telefonia, franquias de cosméticos, redes de supermercados, bancos, operadoras de cartões de crédito, companhias aéreas, franquias de restaurantes e fast-food, serviços de streaming de áudio e vídeo etc. Os comentários foram retirados de respostas dos usuários do Facebook às postagens de marketing das empresas ou da aba de avaliação da empresa ou serviço.

Os comentários foram segmentados em elementary discourse units (EDUs) que, segundo Carlson e Marcu (2001), são os blocos mínimos de construção de uma árvore discursiva. Geralmente as EDUs correspondem a cláusulas (orações), com exceção de orações completivas e de orações restritivas, que não estabelecem relações retóricas.

Uma vez segmentadas as unidades, realizou-se a identificação da UC de cada comentário avaliativo. De acordo com Iruskieta et al. (2015), a UC é o nó central da árvore discursiva, ou seja, a unidade para a qual todas as demais porções de texto apontam. No exemplo da figura 3 apresentada anteriormente neste trabalho, seria a EDU 2. Foi necessário identificar a UC de cada comentário para se verificar a relação estabelecida entre a avaliação do usuário expressa na UC e o restante do comentário. A partir da identificação da UC e da relação estabelecida, foi possível, então, determinar a polaridade positiva ou negativa da avaliação realizada em cada comentário.

Por fim, foram tabuladas a polaridade e a relação retórica de cada ocorrência por meio do Systemic Coder (O’DONNELL, 1995), uma ferramenta que facilita o trabalho de codificação dos dados linguísticos por meio da criação de uma rede sistêmica hierárquica das categorias relevantes para a pesquisa.

\section{Resultados e Discussão}

Como pode ser observado no Quadro 1, a maioria dos comentários do corpus apresenta avaliação negativa.

Quadro 1 - Polaridade das avaliações nos comentários do corpus

\begin{tabular}{|l|c|c|}
\hline POLARIDADE & $\mathbf{N}$ & $\mathbf{\%}$ \\
\hline Negativa & 358 & 72,8 \\
\hline Positiva & 134 & 27,2 \\
\hline Total & 492 & 100 \\
\hline
\end{tabular}

Fonte: Elaborado pelo autor.

Uma justificativa plausível para a frequência bem mais alta de avaliações negativas é o fato de os usuários já terem recorrido a diversos meios para solução de problemas com a empresa fabricante de um produto ou prestadora de um serviço e não terem obtido sucesso. Diante da frustração, muitos usuários tentam criar uma imagem negativa da empresa em sua página pública, como pode ser observado no exemplo $(1)^{5}$.

(1) Como vocês tratam o cliente antigo dessa forma? Vocês não têm a menor noção de fidelização de clientes. A empresa é ingerente, atendentes que ora falam A, ora falam B. Cada um fala uma língua e o cliente que se

\footnotetext{
${ }^{5}$ Os exemplos foram reproduzidos tal como foram encontrados. Não foram feitas correções.
} 
dane. Veja no Inbox a quantidade de protocolos registrados nessa empresa e também na Anatel, simplesmente por pura incompetência na resolução de simples problemas. Quando um empresa negligência os seus clientes, pode acreditar que o seu futuro vai ser decadente, ainda mais com essa intransigência de retirada de emissoras de TV para fechar com chave de ouro. o que resta é ação judicial para reparação financeira e de danos. Nada mais.

Um outro comentário encontrado no corpus - exemplo (2) - apresenta outra hipótese que ajuda explicar a altíssima frequência de avaliações negativas. Uma interpretação plausível do comentário é a de que criticar com mais frequência do que elogiar é um comportamento típico do ser humano.

(2) Comprei um tênis do star wars pro meu filho. Chegou antes do prazo e de muito boa qualidade. Já é o segundo que compro, e nunca tive problemas quanto a qualidade. Criticar é mole, tem que elogiar tb quando merece.

No Quadro 2, apresentam-se as quantidades e as frequências de ocorrência das relações encontradas nos comentários avaliativos do corpus.

Quadro 2-Quantidades e frequências de ocorrência das relações do corpus

\begin{tabular}{|l|c|c|}
\hline RELAÇÃO & $\mathbf{N}$ & $\mathbf{\%}$ \\
\hline Avaliação & 174 & 35,4 \\
\hline Resultado & 122 & 24,8 \\
\hline Motivação & 48 & 9,8 \\
\hline Concessão & 37 & 7,5 \\
\hline Interpretação & 22 & 4,5 \\
\hline Elaboração & 15 & 3 \\
\hline Justificativa & 23 & 4,7 \\
\hline Causa & 25 & 5,1 \\
\hline Contraste & 10 & 2 \\
\hline Antitese & 3 & 0,6 \\
\hline Evidência & 4 & 0,8 \\
\hline Adição & 3 & 0,6 \\
\hline Solução & 2 & 0,4 \\
\hline Total & 492 & 100 \\
\hline
\end{tabular}

Fonte: Elaborado pelo autor.

Por se tratar de um corpus de comentários avaliativos, como era de se esperar, a relação com frequência mais alta de ocorrência é a de avaliação. Segundo Mann e Thompson (1988), a intenção do produtor do texto ao utilizá-la é que seu destinatário reconheça que o satélite $(\mathrm{S})$ avalia o núcleo $(\mathrm{N})$ e reconheça também o valor atribuído a N. No exemplo (3), observa-se que a avaliação positiva é expressa pela expressão "show de bola", ao passo que, no exemplo (4), a avaliação negativa é sinalizada pela expressão "merda de atendimento".

(3) [Show de bola,]S_Avaliação [eu e minha esposa sempre que podemos estamos aí nosso point preferido!]N 
(4) [Merda de atendimento!]S_Avaliação [Primeira vez que me negam um copo com gelo. Tem copo, tem gelo, mas "só pode servir pra suco". Estou bebendo um refrigerante quente nesse calor de 40 graus! THANX por nada... Aqui eu não volto]N

A relação de resultado também apresenta um grande número de ocorrências. De acordo com Mann e Thompson (1988), a intenção do falante ao utilizar essa relação é que seu destinatário reconheça que $\mathrm{N}$ causou a ação ou a situação em S. Como pode ser observado na avaliação positiva do exemplo (5), o resultado da qualidade da comida e do atendimento é que o autor do comentário sempre retornará ao restaurante que está avaliando. Já na avaliação negativa do exemplo (6), o resultado da falta de opções para troca de pontos por produtos no programa de recompensa da empresa avaliada é que o autor da avaliação não irá renovar sua assinatura.

(5) [Comida de excelente procedência, atendimento excepcional.]N [Sempre que for pra Maringá não deixarei de passar por lá.]S_Resultado

(6) [Venho fazer uma reclamação a quase 1 ano tento trocar meus pontos no clube nunca tem nada de bom tenho 403 pontos e minha assinatura vence no próximo mês]N e [não pretendo renova lá caiu muito o nível]S_Resultado

A relação de causa apresenta frequência de ocorrência de pouco mais de $5 \%$. Ao contrário da relação de resultado, na relação de causa, é S que causa N (Mann e Thompson, 1988), como pode ser observado nos exemplos (7) e (8) a seguir. Em (7), a avaliação é positiva, pois as ações de levar o autor do comentário a conhecer músicas legais e saber mais sobre o artista fazem-no amar a empresa de streaming de áudio que está avaliando. Já em (8), escrito intencionalmente como se fosse um e-mail ou uma carta de solicitação a uma outra empresa de streaming, tem no cancelamento de uma série a causa de o relacionamento entre o assinante e a empresa estar abalado.

(7) [Nossa, eu AMO esse tipo post da empresa de streaming X,]N [me faz conhecer várias músicas legais, e de quebra, eu fico sabendo um pouco sobre o artista]S_Causa

(8) [Cara Empresa de Streaming, assim você abala o nosso relacionamento.]N [Eu vejo a série $Y$ assim como eu respiro, não vivo sem, vejo séries novas mas foi essa que eu assisti mais de 10 vezes. Eu sou canceriana. Eu sou apegada. Nenhuma outra série vai substituir ela no meu coração. São anos de relacionamento. Cordialmente, Assinante.]S_Causa

Com frequência próxima de 5\%, a relação de justificativa tem como objetivo, segundo Mann e Thompson (1988), aumentar a prontidão do destinatário para aceitar o direito do falante ou escritor para apresentar o conteúdo de N. Antonio (2012) utiliza a proposta de Hengeveld (1998) para distinguir as relações de causa e resultado da relação de justificativa. Na proposta do gramático holandês, orações de causa se estabelecem entre estados de coisas, ou seja, entidades de segunda ordem, que podem ser avaliadas em termos de sua realização, na taxonomia ontológica dos seres de Lyons (1977). Em outras palavras, um evento causa o outro. Ainda na proposta de Hengeveld, as orações de razão são estabelecidas entre conteúdos proposicionais (entidades de terceira ordem na taxonomia de Lyons), conteúdos que podem ser avaliados em termos de seu valor de verdade. Uma oração de razão não causa o evento da oração principal, mas apresenta o conteúdo que "levou o participante da oração principal a se engajar naquele evento" (HENGEVELD, 1998, p. 346, tradução

${ }^{6}$ led the participant in the main clause event to engage in that main clause event 
nossa). Por fim, as orações explicativas se estabelecem entre atos de fala, que podem ser avaliados em termos de sua informatividade. A oração explicativa é considerada um ato de fala à parte porque expressa as "considerações que levaram o falante a chegar à conclusão contida na oração principal”" (p. 347, tradução nossa). Seguindo a distinção proposta por Hengeveld, Antonio (2012) propõe que, na combinação entre orações adjacentes, as relações de causa e resultado se estabelecem entre entidades de segunda ordem (eventos), se as ações forem não volitivas, ou terceira ordem (conteúdos proposicionais), se as ações forem volitivas. E a relação de justificativa se estabelece entre entidades de quarta ordem (atos de fala).

No exemplo (9), o conteúdo de $\mathrm{S}$ serve para justificar o ato de fala em $\mathrm{N}$, que parabeniza a empresa aérea. Em (10), o autor do comentário justifica o motivo de ter utilizado um tom cínico em seu comentário negativo a respeito do funcionamento da internet na sua empresa provedora de internet.

(9) Parabenizo pela iniciativa]N [.. aconteceu isso comigo e minha família, estávamos com viagem marcada para lá na semana passada, ligamos e prontamente remarcaram nossas passagens sem nenhum empecilho ou custo.. obrigada!]S_ Justificativa

(10) [E bom né que a internet funcione ai] $\mathrm{N}$ [pois aqui em casa tem mais de 15 dias que esta ruim e olha que o modem foi trocado duas vezes e o Wifi ta uma droga. Para abrir um vídeo mais rápido você precisa esta do lado do modem se estiver no outeo comodo demora até para abrir página este modem e uma droga vou comprar um rotiador e colocar na rede para ver se melhora pois esta droga não funciona]S_Justificativa

A relação de motivação apresenta frequência de ocorrência próxima dos 10\%. A partir da proposta de Hengeveld (1998) e do modelo da Gramática Discursivo-Funcional (HENGEVELD; MACKENZIE, 2008), Antonio (2012) explica que a relação de motivação geralmente é expressa por meio de atos discursivos injuntivos, como nos exemplos (11) (“Não adquiram...”) e (12) (“... troquem a trilha...”).

De acordo com Mann e Thompson (1988), ao utilizar a relação de motivação, o falante tem como intenção aumentar o desejo do destinatário de realizar a ação em N. No corpus da pesquisa, foram encontrados dois usos distintos dessa relação: um uso voltado para o leitor dos comentários da página da empresa e outro voltado para a própria empresa. No caso do exemplo (11), o autor do comentário se dirige aos leitores de sua postagem, com a intenção de convencê-los a não adquirirem o serviço de internet X. A motivação para que eles não adquiram o serviço é apresentada em $\mathrm{S}$ por meio dos inúmeros problemas relatados pelo autor da avaliação. Já no caso do exemplo (12), o autor do comentário se dirige à empresa, tentando convencê-la a trocar a música da chamada de espera. A motivação para isso é apresentada em S.

(11) [Não adquiram serviço de internet X!!!]N [Assino $20 \mathrm{Mb}$, mas há meses a operadora X só me entrega metade, chegando a cair para $4 \mathrm{Mb} /$ seg. O WI-FI então é só para enfeite? Onde está a fiscalização da Agência Reguladora $X$, do Programa de Defesa do Consumidor do Estado X? Tenho os prints arquivados, pois se chamo um técnico, ele consulta o speed teste apenas uma vez e ainda coloca defeito nos meus equipamentos particulares, ao invés de solucionar os problemas causados por essa falcatrua da operadora X (com modem sem antena externa de WIFI)! Perde-se um turno inteiro esperando por um técnico, eles enrolam e não consertam nada!! Muita raiva dessa falta de RESPEITO! A operadora X é só conversa, não tem ação/solução! QUERO INTERNET! Está paga (débito em conta), PAGAMENTO NUNCA ATRASOU!!!]S_Motivação

(12) Por amor aos nossos ouvidos, troquem a trilha da chamada de espera.]N [Além de esperar pra falar com alguém (por um longo período aliás) esses ruídos são altos demais!!!!]S_Motivação

7 considerations that led the speaker to arrive at the conclusion contained in the main clause 
A relação de concessão apresenta frequência de ocorrência de 7,5\%. Thompson e Mann (1985) propõem que a concessão seja concebida não em termos semânticos, mas em termos textuais, como uma relação discursiva. Segundo os autores, em uma abordagem discursiva, as orações não podem ser consideradas isoladamente, pois não seria possível inferir os objetivos do autor do texto. Somente em termos de contexto discursivo pode-se compreender como a concessão é uma 'concessão' de algo: ela concede a incompatibilidade potencial de duas situações para antecipar uma objeção que poderia interferir na crença do destinatário a respeito do argumento que o autor defende.

No caso da avaliação positiva do exemplo (13), o autor defende que o cartão de crédito que ele está avaliando é "perfeito em tudo", com exceção dos problemas apresentados em S. Em outras palavras, apesar de o leitor esperar, a partir das informações presentes em S, que o autor do comentário avaliaria negativamente o cartão, em N essa expectativa é quebrada. No exemplo de avaliação negativa (14), já apresentado anteriormente na Figura 3, a aparente incompatibilidade se dá entre o fato de o veículo avaliado pelo autor do comentário ser um "carrão" e o fato de sua manutenção ser caríssima. A leitura de $S$ indicaria uma avaliação positiva, mas os fatos apresentados em $\mathrm{N}$ quebram essa expectativa, concluída com a decisão do autor do comentário de nunca mais adquirir veículos daquela montadora.

(13) [Comigo sempre libera no dia seguinte. Pago pela Internet. Só tem uma desvantagem, não aumentam o limite. Tenho 1,8k e meu irmão que tá sem emprego no momento conseguiu 4k de limite.]S_Concessão [Fora isso eh perfeito em tudo!]N

(14) [Realmente um carrão....]S_Concessão [pena que a manutenção inviabiliza a aquisição....a minha com $97.000 \mathrm{~km}$...precisei gastar $\mathrm{R} \$ 21.300,00$ para botar pra funcionar novamente....um verdadeiro roubo..... Montadora $X$ nunca mais....]N

A relação de interpretação, que tem 4,5\% de ocorrências, é utilizada, segundo Mann e Thompson (1988), para adicionar informações ao conteúdo de $\mathrm{N}$, as quais, apesar de não estarem diretamente associadas a N, auxiliam na compreensão de seu conteúdo. De acordo com Santos (2018, p. 86),

Carlson e Marcu (2001) expandem o que foi originalmente proposto por Mann e Thompson (1988), pois pontuam que a interpretação é uma relação subjetiva, que apresenta uma opinião pessoal do falante ou de um terceiro, podendo ser 1) uma explicação de algo que não é imediatamente claro ou explícito; 2) uma explicação de ações ou eventos, ou declarações que apontam ou sugerem relações interiores ou motivos ou, ainda, relacionam características particulares a princípios gerais; 3) um entendimento ou apreciação de uma situação à luz de crença individual, julgamento, interesse ou circunstância.

Nos exemplos encontrados no corpus, o uso da relação de interpretação expressa ironia ou cinismo por parte do autor do comentário, como no exemplo (15).

(15) [Minha televisão modelo \#\#\#\#\#\#\# durou exatos 7 meses...]N [Pelo menos ela não explodiu que nem alguns celulares, por isso agradeço a Empresa X]S_Interpretação

A relação de comentário, que não faz parte do rol clássico de relações da RST definidas por Mann e Thompson (1988), também é utilizada pelos autores dos comentários de forma cínica, irônica ou jocosa. Essa relação foi proposta por Carlson e Marcu (2001), que a definem

como uma relação em que o satélite apresenta uma marca subjetiva do falante a respeito do que é dito na porção de texto anterior. [...] Ademais, os autores apontam que normalmente o comentário é apresentado de uma perspectiva de fora dos elementos focalizados no núcleo (apud SANTOS, 2018, p. 95). 
No corpus, essa relação teve frequência de ocorrência de 0,8\% e, no exemplo (16), pode-se observar que em $\mathrm{S}$ o usuário do Facebook faz um comentário jocoso a respeito do conteúdo de $\mathrm{N}$.

(16) [Que nave ! Muito lindo]N [geralmente quem reclama dele pilota uma (o autor do comentário menciona alguns modelos de motos populares) kkkkkkkkkkkkkkkkkkk mais brincadeiras a parte essa máquina ta fera demais !!! S_Comentário

A relação de elaboração, embora geralmente seja a mais frequente na maioria dos corpora investigados utilizando-se o arcabouço teórico-metodológico da RST (TABOADA; HABEL, 2013), no corpus deste trabalho apresentou frequência de ocorrência de apenas 3\%. Na elaboração, o destinatário do texto reconhece que $\mathrm{S}$ fornece detalhes adicionais a respeito de N. A baixa frequência de ocorrência no corpus deste trabalho talvez possa ser explicada pelo fato de essa relação ter apenas viés semântico (acréscimo de detalhes). No corpus, como predominam comentários avaliativos, a intenção dos autores dos comentários é convencer seus destinatários a respeito da qualidade (ou falta dela, na maioria das vezes) de um produto ou serviço. $\mathrm{Na}$ avaliação positiva de (17), o autor do comentário elabora, em S, o "presente super fofo" que recebeu. $\mathrm{Na}$ avaliação negativa de (18), o autor do comentário elabora, em S, o desconforto da poltrona em seu voo.

(17) [Que lindo d' Sou cliente a 2 meses e já recebi um presente super fofo.]N [Entrei no chat dizendo que precisava aumentar um pouco meu limite que iria pra Buenos Aires em março, e tive a solicitação atendida super rápido pela atendente $M$. no chat; e hoje me deparo com esta gentileza que só um cartão como o cartão $x$ que se preocupa com as pessoas pode nos proporcionar, uma carta de cunho manual toda carinhosa e um travesseiro de viagemd']S_Elaboração

(19) [Voei hoje de Congonhas para Porto Alegre e o desconforto da poltrona foi algo que não vivenciava a muito tempo.] [Simplesmente parecia não ter espuma no encosto das costas, e que eu estava apoiado apenas nas madeiras do assento. O número do voo era \#\#\#\# e os demais passageiros que estavam na mesma fileira que eu reclamaram pelo mesmo motivo.]S_Elaboração

A única relação multinuclear encontrada com função avaliativa no corpus foi a de contraste, com frequência de ocorrência de apenas $2 \%$. Devido à natureza da relação, como pode ser observado em (20), o comentário é neutro, pois apresenta tanto aspectos positivos quanto negativos do colégio avaliado, sem atribuir maior peso a nenhuma das polaridades.

(20) [Tem professores MUITO bons, um excelente suporte pra alunos, a atmosfera é mais light e liberal,]N_Contraste [de pontos negativos são coisas pequenas, tipo a cantina, pouca coisa boa e relativamente cara e ter biologia como disciplina de maior carga horária]N_Contraste

A relação de antítese, com frequência de apenas $0,6 \%$ no corpus, é próxima semanticamente da relação de contraste, pois suscita uma incompatibilidade entre duas situações. No entanto, seu uso tem como objetivo aumentar a atitude positiva do destinatário do texto em relação a N. No caso do exemplo (21), o autor do comentário destaca a falta de compatibilidade entre duas atitudes de uma empresa telefônica: postar matérias interessantes e não tratar os clientes de forma digna, destacando em $\mathrm{N}$ esta última atitude.

(21) [Postar esse tipo de matéria é muito interessante.]S_Antítese [Mas difícil mesmo é dar um atendimento digno ao seu cliente. Venho tendo problemas com meu serviço há meses e simplesmente não consigo contato 
eficaz. Ninguém resolve meu problema e eu continuo sem internet (e pagando uma conta bem cara, por sinal). Será que terei que recorrer à ANATEL mais uma vez para ser atendido? Preciso implorar para ser atendido e para ter meu problema resolvido? O seu serviço está ridículo e estou muito insatisfeito. Irei recorrer a medidas legais para tentar ser atendido. Trabalho com internet e dependo dá mesma para o meu sustento. Não aguento mais!]N

Assim como a relação de antítese, a relação de adição também tem frequência de ocorrência de apenas $0,6 \%$. Essa relação também não faz parte do rol clássico de relações definidas por Mann e Thompson (1988). Foi definida por Antonio e Santos (2014) com base na definição de orações hipotáticas aditivas, de Halliday (1985), como sendo utilizada para acrescentar, em S, um argumento favorável à conclusão de N. No exemplo (22), o autor do comentário apresenta, em S, um argumento que reforça a avaliação positiva de N. É interessante se observar que o item "mas", que introduz S, é utilizado como marcador discursivo. No exemplo (23), um argumento que reforça a avaliação negativa de N é apresentada em S, introduzido pelo item "aliás".

(22) [Sou de Porto Alegre e vim experimentar as famosas empanadas na unidade do Jardim Paulista. Surpreendida pela localização dentro de uma livraria, que deixou o local ainda mais charmoso. Música excelente, conforto apesar do ambiente simples e rústico; funcionárias atenciosas e dinâmicas.]N [Mas o melhor foi o prazer de degustar um mix de sabores distribuídos com perfeição em cada empanada. E as sobremesas? Um deleite para o paladar!!!]S_Adição

(23) [podiam aumentar a quantidade de recheio do prato $X$ ao invés do tempo do festival... Domingo fomos na Unidade do Shopping $X$ e foi bem decepcionante a quantidade de costela dentro da quesadilla...]N [Aliás, a unidade do Shopping $X$ quase sempre tem algo fora do padrão. Seja comida com pouco recheio, chá sem gosto parecendo água suja, aperitivos em porções menores do que o normal... Por mais que após reclamar eles resolvam, é chato ter que ficar reclamando quase sempre. Completamente diferente da unidade do Shopping Y ou qualquer outra unidade do restaurante Z.]S_Adição

A relação de evidência apresenta $0,8 \%$ de frequência de ocorrência no corpus. De acordo com Mann e Thompson (1988), a intenção do produtor do texto ao utilizá-la é de aumentar a confiança do destinatário no conteúdo de N. No exemplo (24), o autor do comentário apresenta uma evidência para comprovar a afirmação feita em N.

(24) [Já foi o tempo q a montadora $X$ fazia carros bons e duradouros.]N [Exemplo disso foram os carros $X$ com motor X]S_Evidência

Por fim, a relação de solução é a que apresenta frequência de ocorrência mais baixa: 0,4\%. Na definição de Mann e Thompson (1988), o produtor do texto apresenta em S uma solução para o problema exposto em N. No exemplo (25), o autor do comentário critica o borrifador do produto que está avaliando e sugere, como solução, que a empresa mude ou melhore o produto.

(25) [O Borrifador dá muito problema,]N [poderiam mudar ou melhorar esse problema]S_Solução

\section{Considerações Finais}

Este trabalho teve como objetivo descrever as relações retóricas que emergem de comentários 
avaliativos em páginas públicas de empresas no Facebook tomando como base a RST, teoria descritiva que investiga a organização dos textos caracterizando as relações que se estabelecem entre as partes do texto.

Os comentários que compõem o corpus do trabalho foram retirados de respostas dos usuários do Facebook às postagens de marketing das empresas ou da aba de avaliação da empresa ou serviço. Os comentários foram segmentados em EDUs e, na sequência, realizou-se a identificação da UC de cada comentário avaliativo. Por fim, foram tabuladas a polaridade e a relação retórica de cada ocorrência.

Em termos de polaridade, mais de $70 \%$ das ocorrências apresenta polaridade negativa, provavelmente pelo fato de os usuários já terem recorrido a diversos meios para solução de problemas com a empresa fabricante de um produto ou prestadora de um serviço e não terem obtido sucesso. Diante da frustração, muitos usuários tentam criar uma imagem negativa da empresa em sua página pública.

Foram encontrados 14 tipos de relações retóricas no corpus. As relações de avaliação e resultado são as que apresentam frequência de ocorrência mais alta. Por se tratar de um corpus de comentários avaliativos, é natural que essa relação seja a mais utilizada. A alta frequência da relação de resultado pode ser explicada pelo fato de a intenção do falante ao utilizar essa relação é que seu destinatário reconheça que $\mathrm{N}$ causou a situação em S, ou seja, bom atendimento, qualidade dos produtos resultam em satisfação do cliente. Por outro lado, mau atendimento e produtos de má qualidade resultam em reclamações por parte do cliente.

Espera-se que este trabalho tenha contribuído tanto com a análise de sentimentos quanto com a RST. Em trabalhos futuros, pretende-se utilizar esse corpus para verificar se as relações retóricas podem auxiliar no processo de análise automática da polaridade, uma vez que nem sempre a polaridade dos itens lexicais presentes na avaliação indica a polaridade corretamente (veja-se no caso da ironia, por exemplo).

\section{REFERÊNCIAS}

ALKORTA, J.; GOJENOLA, K.; IRUSKIETA, M.; PÉREZ, A. Using relational discourse structure information in Basque sentiment analysis. In: WORKSHOP RST AND DISCOURSE STUDIES, 5., 2015, Alicante. Proceedings... Alicante, ES: SEPLN, 2015.

ANTONIO, J. D. Expression of cause, evidence, justify and motivation rhetorical relations by causal hypotactic clauses in Brazilian Portuguese. Acta Scientiarum, Language and Culture, v. 34, n. 2, p. 253-268, jul./dez. 2012.

ANTONIO, J. D.; SANTOS, J. A. A estrutura retórica do gênero resposta argumentativa. Signum: Estudos da Linguagem, Londrina, v. 17, n. 2, p. 193-223, 2014. Disponível em: https://bit.ly/3qy50wS.

CARLSON, L.; MARCU, D. Discourse Tagging Reference Manual. Los Angeles, CA: University of Southern California, 2001.

DE HAAN, F. The relation between modality and evidentiality. Linguistische Berichte, v. 9, p. 201-216, 2001.

FACEBOOK. Informações da empresa. Disponível em: http://bit.ly/3qEsBfn. Acesso em: 08 out. 2018.

HALLIDAY, M. A. K. An introduction to Functional Grammar. Baltimore: Edward Arnold, 1985.

HENGEVELD, K. Adverbial clauses in the languages of Europe. In: AWERA, J. (org.). Adverbial constructions in the languages of Europe. Berlin: Mouton de Gruyter, 1998. p. 335-419. 
HENGEVELD, K.; MACKENZIE, J. L. Functional Discourse Grammar. A typologically-based theory of language structure. Oxford: Oxford University Press, 2008.

HOGENBOOM, A.; FRANSINCAR, F.; DE JONG, F.; KAYMAK, U. Using rhetorical structure in sentiment analysis. Communications of the ACM, v. 58, n. 7, p. 69-77, July 2015.

IRUSKIETA, M.; DE ILARRAZA, A. D.; LABAKA, G.; LERSUNDI, M. The Detection of Central Units in Basque scientific abstracts. In: CONGRESO DE LA SOCIEDAD ESPAÑOLA DEL

PROCESAMIENTO DEL LENGUAJE NATURAL, 31., 2015, Alicante. Actas... Alicante, ES: SEPLN, 2015.

LYONS, J. Semantics. Cambridge: Cambridge University Press, 1977.

MANN, W. C.; THOMPSON, S. A. Rhetorical Structure Theory: toward a functional theory of text organization. Text, v. 8, n. 3, p. 243-281, 1988.

MATTHIESSEN, C. Remembering Bill Mann. Computational Linguistics, v. 31, n. 2, p. 161-172, 2005.

O'DONNELL, M. From corpus to codings: Semi-automating the acquisition of linguistic features.

Proceedings of the AAAI Spring Symposium on Empirical Methods in Discourse Interpretation and Generation. Anais... Stanford: AAAI, 1995. p. 27-29.

PALMER, F. R. Mood and modality. Cambridge: Cambridge University Press, 1986.

SANTOS, K. R. Uma investigação funcionalista das relações retóricas do campo da avaliação no português falado. 2018. Dissertação (Mestrado em Letras) - Universidade Estadual de Maringá, Maringá, 2018.

SEIDMAN, G. Expressing the "true Self" on Facebook. Computers in Human Behavior, v. 31, n. 1, p. 367-372, 2014.

TABOADA, M. Implicit and explicit coherence relations. In: RENKEMA, J. (ed.). Discourse, of course. Amsterdam: John Benjamins, 2009. p. 127-140.

TABOADA, M. Sentiment analysis: An overview from Linguistics. Annual Review of Linguistics, v. 2, n. 1, p. 325-347, 2016.

TABOADA, M.; HABEL, C. Rhetorical relations in multimodal documents. Discourse Studies, v. 15, n. 1, p. 65-89, 2013.

THOMPSON, S. A.; MANN, W. C. A Discourse view of concession in written English. In: DELANCEY, S. C.; TOMLIN, R. S. (org.). ANNUAL PACIFIC LINGUISTICS CONFERENCE, 2., 1985. Proceedings... Eugene, OR: Department of Linguistics/University of Oregon, 1985. p. 435-447.

TRAUGOTT, E. C. Subjectification, Intersubjectification and grammaticalization. In: DAVIDSE, K.; VANDELANOTTE, L.; CUYCKENS, H. (org.). (Inter)subjectivity and (inter)subjectification: a reassessment. Berlin: de Gruyter, 2010. p. 29-74. 
TRNAVAC, R.; TABOADA, M. Discourse structure and attitudinal valence of opinion words in sentiment extraction. Linguistic Society of America Annual Meeting Extended Abstracts. Proceedings... Minneapolis, MN: Linguistic Society of America, 2014. p. 1-5.

WILSON, R. E.; GOSLING, S. D.; GRAHAM, L. T. A review of Facebook Research in the Social Sciences. Perspectives on Psychological Science, v. 7, n. 3, p. 203-220, 2012.

ZELDES, A. rstWeb - A browser-based annotation interface for rhetorical structure theory and discourse relations. In: NAACL-HLT 2016 SYSTEM DEMONSTRATIONS, San Diego. Proceedings... San Diego, CA: NAACL, 2016. p. $1-5$. 